\title{
Hadesarchaea and other extremophile bacteria from ancient mining areas of the East Harz region (Germany) suggest an ecological long-term memory of soil
}

\author{
J. Michael Köhler ${ }^{1,2}$ (D) Franziska Kalensee ${ }^{1,2} \cdot$ Jialan Cao $^{1,2} \cdot$ P. Mike Günther ${ }^{1,2}$
}

C Springer Nature Switzerland AG 2019

\begin{abstract}
The 165 rRNA profiling of 27 soil samples of three ancient mining areas of the East Harz region (Germany) indicated a group of rare bacteria which is related to extreme conditions such as salinity, higher temperature and alkalinity. Beside Hadesarchaea, it involves a significant number of sequences of Rubritepida, Polymorphobacter, Crinalium, Aliterella, Imperialibacter, Mizugakiibacter, Ekhidna, Mumia and Isoptericola, too. The appearance of such types may be related to the ground material which was brought onto the surface by the ancient mining activities dating back into the period between the fifteenth and the beginning nineteenth centuries. It is assumed that the RNA profiling reflects local soil bacteria communities which store a certain memory of previous environmental conditions. This ecological memory could be related on the one hand to the minerals and the mining activities centuries before, but on the other hand it could hint to the possibility of storage of bacteria in the geological sediments of late Perm (Zechstein), which has been deposited about 250 million years ago. The findings can be interpreted by the possibility of persistence of special types of soil bacteria at the ancient mining places. In addition, a possible relevance of the re-activation of very old microorganisms from deep subsurface layers for the recent microbial communities should be taken into account. Graphic abstract
\end{abstract}

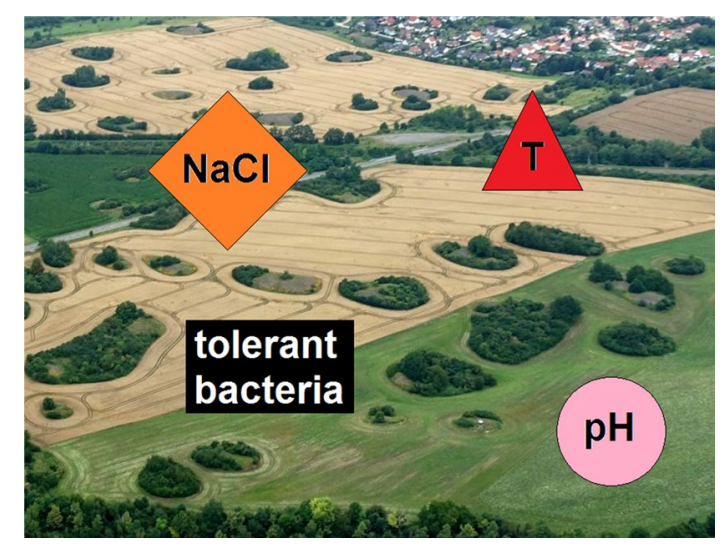

Keywords Soil bacteria $\cdot$ Microbial communities $\cdot 16 \mathrm{~S}$ rRNA profiling $\cdot$ Copper mining $\cdot$ Archaea Electronic supplementary material The online version of this article (https://doi.org/10.1007/s42452-019-0874-9) contains
supplementary material, which is available to authorized users.

\footnotetext{
$\triangle$ J. Michael Köhler, michael.koehler@tu-ilmenau.de $\left.\right|^{1}$ Institute for Micro- und Nanotechnologies, Technical University Ilmenau, PF10 05 65, 98684 Ilmenau, Germany. ${ }^{2}$ Department of Physical Chemistry and Microreaction Technology, Institute for Chemistry and Biotechnology, Technical University Ilmenau, PF10 05 65, 98684 IImenau, Germany.
}

SN Applied Sciences (2019) 1:839| https://doi.org/10.1007/s42452-019-0874-9 


\section{Introduction}

Microbial diversity is a key issue for the responsivity of soils to environmental stress and is therefore crucial for the protection of soils and for the adaptation of whole biological communities to changing environments $[7,8]$. Despite physiological active microbial populations, the dormant part of microorganisms is mainly responsible for this responsivity [1]. Typically, the dormant organisms form the overwhelming part of taxonomical units in each biocenosis and are mainly responsible for diversity and flexible responsivity of microbial communities [14].

The dormant and the very slowly growing and dividing microoorganisms represent a kind of memory for ecological conditions of a biotope in the past. It is well known that bacteria can be stored in ice blocks [12] for longer time and can survive in glacial and postglacial sediments over thousands of years [23,31]. Probably, even storage of bacteria over huge time scales is possible as investigations on inclusions in Permian salt deposits suggest [28]. Despite geological memory effects, even special historic or prehistoric situations can cause special local components in microbial communities which are related to ancient human activities $[15,21]$.

Therefore, the natural soil microbial communities are not only affected by recent activities like agriculture, cattle breeding or industry, but can also be influenced by ancient land use and long-term memory effects. In particular, mining and smelting have an important impact on the composition of microbial communities [11] due to bringing deep mineral material onto the surface and by the liberation of toxic components as heavy metals, for example Haferburg and Kothe [10]. The specific conditions on mining areas have a strong impact on the composition and diversity of soil microorganisms. Recent studies show that acid mine drainage, in particular, promotes the formation of distinct local microbial populations [22]. New investigations show that archaea have a high abundance in extremely acidic mine-impacted environments [18]. But, the composition of soil bacterial communities is strongly dependent on acidity [20] and differs significantly between moderate and low pHs [17].

In addition, one has to take in mind that also long-term dormant and very slowly growing and dividing microbial strains from deep geological layers could be brought unto the surface, come in contact with physiologically active soil and waked up for proliferation. Thus, the ecological memory of mining places could mirror specific effects of the mineral component on the biocenosis as well as the reactivation of long-term stored dormant microbial components [13]. It is assumable that historical mining places on which the mining activities had been terminated centuries ago could of particular interest for identification of longterm memory effects and for conclusions on the ecological impact of ancient human activities on the recent state of local environments.

The East Harz region (Germany) regarded here has about 800 years history of copper mining with a high mining activity with hundreds of small pre-industrial single mines distributed over large areas between the fifteenth and the beginning of the nineteenth centuries. Therefore, it is an interesting model region for studying the effect of mining on the recent ecological situation [27]. Here, 27 soil samples from three areas of the East Harz region have been chosen for investigation of indications of special patterns or ecological memory effects in the soil bacterial communities.

\section{Experimental}

\subsection{Soil samples}

Samples were collected from melting areas (E09, E83, E85, E87 and E88) and from shaft areas (all others). In the case of shafts, the samples were taken from the shaft material deposited immediately around the shaft holes. The soil material was filled into sterile $50-\mathrm{mL}$ sample tubes and stored and transported by them into the laboratory. The sampling locations are identified by GPS. The sites and GPS coordinates are given in Table 1.

The majority of samples are originating from soil at ancient shaft areas, whereby dry soil material with low grain sizes and a certain portion of humus was preferably used for the taking of samples in all cases (Fig. 1a-e). Samples from slag areas have not been taken from inside of slag pieces, but from soil between slag pieces and from the recent humus-forming soil on the surface of larger melting areas. There was no direct thermal treatment of soil or soil samples. The used surface areas were not directly covered by vegetation. The samples are taken from the immediate environment of the shafts. The shafts are closed in all cases. The surface of the immediate environment of the shafts is not under agricultural use. These small areas represent fallow land. The sample origin is described in Table 1. The soil samples have been characterized by $\mathrm{pH}$ and electrical conductivity measurements. Therefore, $1 \mathrm{~g}$ of soil material of each sample was suspended in $5 \mathrm{ml}$ bi-distilled water. The obtained measurement values are tabled (supplementary table).

Probably, the earliest phase of copper mining in the region started near Hettstedt around the year 1200 [6]. The mining near Rodishain dates back to the fifteenth century. The copper mining near Uftrungen and Breitungen was most intensive in the eighteenth century, particularly 
Table 1 Origin of soil samples

\begin{tabular}{|c|c|c|c|c|c|}
\hline \multicolumn{4}{|c|}{ Sample from mining and melting areas } & \multicolumn{2}{|l|}{ GPS coordinates } \\
\hline Location & Samples & GK (right) & GK (high) & Latitude (grad) & Longitude (grad) \\
\hline Bornstedt & E01 & 4465,027 & 5703,552 & 51 grd $27.930629^{\prime}$ & 11 grd $29.712305^{\prime}$ \\
\hline Wolferode & E04 & 4466,647 & 5707,692 & 51 grd 30.169101' & 11 grd 31.087443' \\
\hline Wolferode & E06 & 4465,662 & 5707,686 & 51 grd 30.162317' & 11 grd $30.236365^{\prime}$ \\
\hline Wimmelburg $\left(^{*}\right)$ & E09 & 4466,29 & 5709,828 & 51 grd 31.319708' & 11 grd $30.766682^{\prime}$ \\
\hline Hergisdorf & E18 & 4463,996 & 5711,089 & 51 grd 31.991207' & 11 grd 28.775918' \\
\hline Erdeborn & E35 & 4471,743 & 5704,899 & 51 grd 28.679611' & 11 grd 35.504267' \\
\hline Oberhütte $\left(^{*}\right)$ & E83 & 4468,594 & 5712,73 & 51 grd $32.892660^{\prime}$ & 11 grd $32.742781^{\prime}$ \\
\hline Oberhütte $\left(^{*}\right)$ & E85 & 4469,108 & 5712,222 & 51 grd 32.620418' & 11 grd $33.190044^{\prime}$ \\
\hline Oberhütte $\left(^{*}\right)$ & E87 & 4469,364 & 5711,689 & 51 grd 32.333827' & 11 grd $33.414238^{\prime}$ \\
\hline Oberhütte $\left(^{*}\right)$ & E88 & 4469,29 & 5711,667 & 51 grd $32.321720^{\prime}$ & 11 grd $33.350361^{\prime}$ \\
\hline Wiederstedt & E19 & 4465,778 & 5726,125 & 51 grd $40.106202^{\prime}$ & 11 grd $30.228481^{\prime}$ \\
\hline Arnstedt & $\mathrm{E} 22$ & 4464,656 & 5727,151 & 51 grd $40.655298^{\prime}$ & 11 grd $29.259216^{\prime}$ \\
\hline Arnstedt & E23 & 4464,895 & 5727,149 & 51 grd $40.655121^{\prime}$ & 11 grd 29.456536' \\
\hline Hettstedt & E25 & 4466,665 & 5723,551 & 51 grd $38.721362^{\prime}$ & 11 grd $31,012471^{\prime}$ \\
\hline Hettstedt & E26 & 4466,548 & 5723,573 & 51 grd $38.732808^{\prime}$ & 11 grd $30.910930^{\prime}$ \\
\hline Welfesholz & E29 & 4470,244 & 5721,753 & 51 grd $37.763848^{\prime}$ & 11 grd 34.123903' \\
\hline Welfesholz & E31 & 4469,068 & 5721,957 & 51 grd $37.870040^{\prime}$ & 11 grd 33.103834' \\
\hline Burgörner & E61 & 4467,222 & 5721,981 & 51 grd $37.526017^{\prime}$ & 11 grd $31.504114^{\prime}$ \\
\hline Burgörner & E63 & 4467,258 & 5722,002 & 51 grd 37.888145' & 11 grd 31.535191' \\
\hline Burgörner & E64 & 4467,256 & 5722,008 & 51 grd $37.891374^{\prime}$ & 11 grd 31.533424' \\
\hline Burgörner & E65 & 4467,32 & 5722,189 & 51 grd 37.989204' & 11 grd 31.587865' \\
\hline Breitungen & Q03 & 4433,304 & 5707,555 & 51 grd 29.917908' & 11 grd 2.280297' \\
\hline Rodishain & Q25 & 4424,444 & 5712,399 & 51 grd 32.462807' & 10 grd $54.563976^{\prime}$ \\
\hline Rodishain & Q29 & 4424,16 & 5712,28 & 51 grd 32.396356' & 10 grd 54.319948' \\
\hline Uftrungen & Q32 & 4430,82 & 5707,821 & 51 grd $30.043409^{\prime}$ & 11 grd $0.121242^{\prime}$ \\
\hline Uftrungen & Q37 & 4431,432 & 5707,589 & 51 grd 29.922790' & 11 grd $0.662680^{\prime}$ \\
\hline Uftrungen & Q42 & 4431,725 & 5707,443 & 51 grd 29.846195' & 11 grd 0.917499' \\
\hline
\end{tabular}

*Melting and slag deposit areas

between 1715 and 1774. The majority of the numerous small mines near Hettstedt, Welfesholz, Wiederstedt, Wolferode and Hergisdorf originated at the latest from the end of eighteenth and the beginning of the nineteenth centuries [6].

\subsection{DNA extraction and data processing}

DNA was extracted from the samples by a Power Soil Isolation Kit (MO BIO, Carlsbad, USA) according to the manufacturer's protocol and processed as published [15]. An Edvocycler (Edvotek, Washington DC) was applied for PCRs. Each PCR amplification step was verified by gel electrophoresis, using $1.2 \%$ agarose gels. Single PCR products as well as pooled DNA libraries were purified with AMPure XP beads (Beckman Coulter, Brea, USA).

For amplicon PCR adaptor, primers A519F-Ad (5' TCG TCGGCAGCGTCAGATGTGTATAAGAGACAGCAGCMGCCGCG GTAA 3') and Bact_805R-Ad (5'-GTCTCGTGGGCTCGGAGA
TGTGTATAAGAGACAGGACTACHVGGGTATCTAATC 3') were used $(100 \mathrm{pmol} / \mu \mathrm{l})$, which were obtained from Eurofins Genomics (Ebersberg, Germany). The reaction mixtures with a total volume of $50 \mu \mathrm{l}$ per reaction contained $1 \mu \mathrm{l}$ of DNA isolation eluate, $2 \mathrm{mM} \mathrm{MgCl} 2,200 \mu \mathrm{M}$ PCR nucleotide mix, 1.25 Units GoTaq G2 Flexi DNA Polymerase, nucleasefree water (all reagents from Promega Madison (USA)) and $1 \mu \mathrm{mol} / \mathrm{l}$ of each primer. Amplicon PCR program settings were as follows: $94^{\circ} \mathrm{C}$ for $5 \mathrm{~min}, 30$ cycles of denaturation at $94{ }^{\circ} \mathrm{C}$ for $30 \mathrm{~s}$; annealing at $50^{\circ} \mathrm{C}$ for $30 \mathrm{~s}$; extension at $72{ }^{\circ} \mathrm{C}$ for $30 \mathrm{~s}$; and a final extension at $72{ }^{\circ} \mathrm{C}$ for $5 \mathrm{~min}$ ).

The automatic software pipeline of the SILVAngs data analysis service $[25,32]$ was used for the community analysis of the NGS data. All data files from GATC Biotech first had to be converted from fastq file format to fasta file format, because the fastq file format was not compatible to upload. The used fastq-to-fasta converter software was "phred33 conversion" from MR DNA Lab. All data sets were analyzed using the preset parameters of the settings page and with the SILVAngs database release version 128 [32]. 
During this automated process, all reads were aligned using the SILVA Incremental Aligner [SINA SINA v1.2.10 for ARB SVN (revision 21008)] [24] against the SILVA SSU rRNA SEED and quality controlled [25]. Reads with fewer of 50 aligned nucleotides and reads with more than two percent of ambiguities, or two percent of homopolymers, respectively, are not processed. Also, reads with a low alignment quality (adjusted minimal alignment identity of $50 \%$ as well as minimal alignment score of 40 reported by SINA) were excluded from downstream analysis. After this first quality check process, the SILVA pipeline identified identical reads and then clustered all unique reads to OTUs using cd-hit-est (version 3.1.2; http://www.bioinformatics.org/ cd-hit) [30] running in accurate mode, ignoring overhangs and applying minimal identity criteria of $98 \%$. The classification of the OTUs through SILVA was performed by a nucleotide BLAST search against the non-redundant version of the SILVA SSU Ref dataset (release 132; http:// www.arb-silva.de) using blastn (version 2.2.30+; http:// blast.ncbi.nlm.nih.gov/Blast.cgi) with standard settings [5]. The classification of each OTU reference read was mapped onto all reads that were assigned to the respective OTU. All reads without any BLAST hits or reads with weak BLAST hits (arithmetic average of sequence identity percentage and alignment coverage percentage below a value of 93\%) were not classified. These reads were assigned to the meta-group "No Relative."
Fig. 1 Historical copper mining area of the East Harz region near Arnstedt and Wiederstedt (Northwest of Hettstedt, Germany), a arial image; the sampling place of E23 is marked by the red arrow, b E09 (Wimmelburg), c E19 (Wiederstedt), d E23 (Arnstedt), e E31 (Welfesholz)

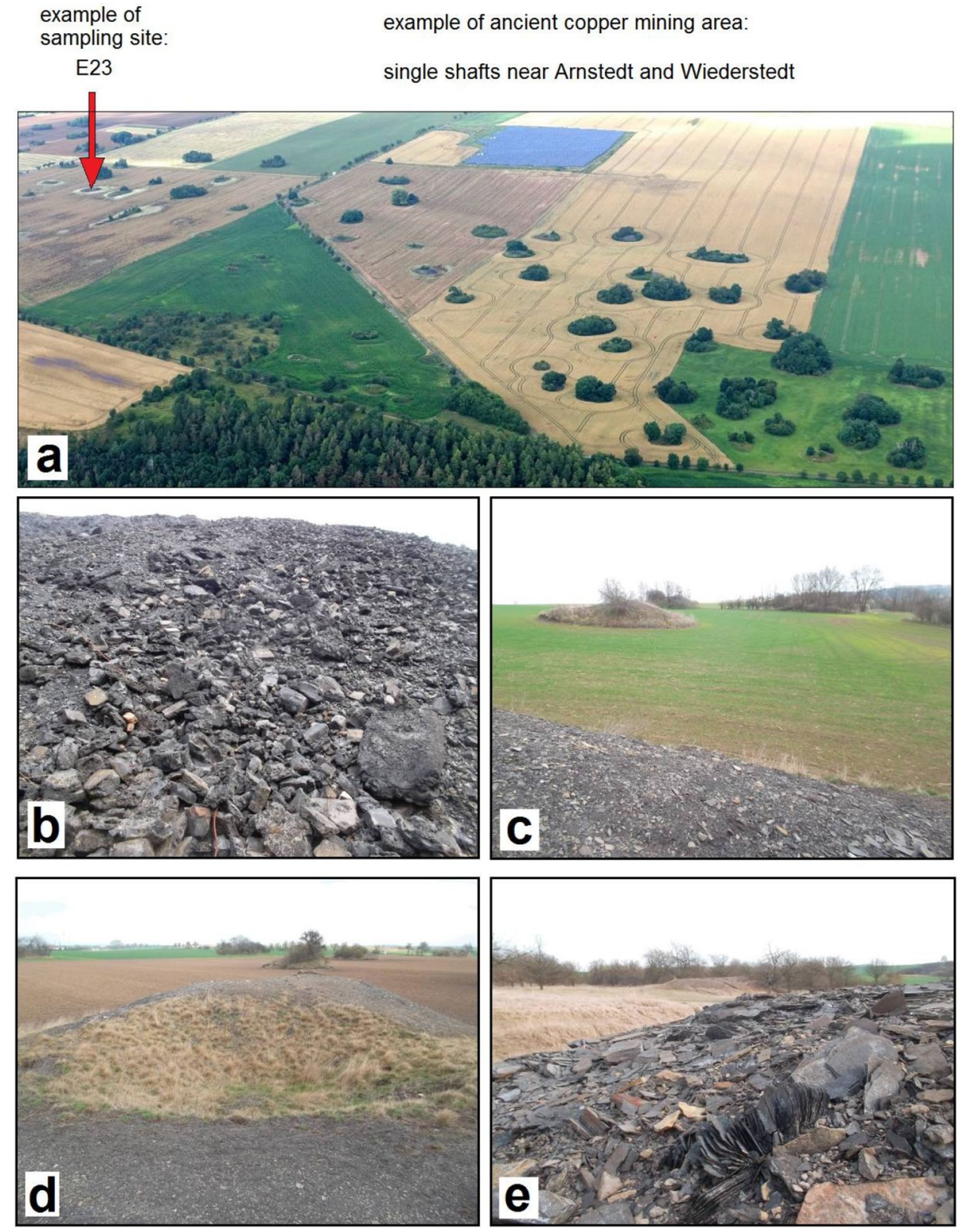


Fig. 2 Soil group-specific presence of selected OTUs in the investigated samples

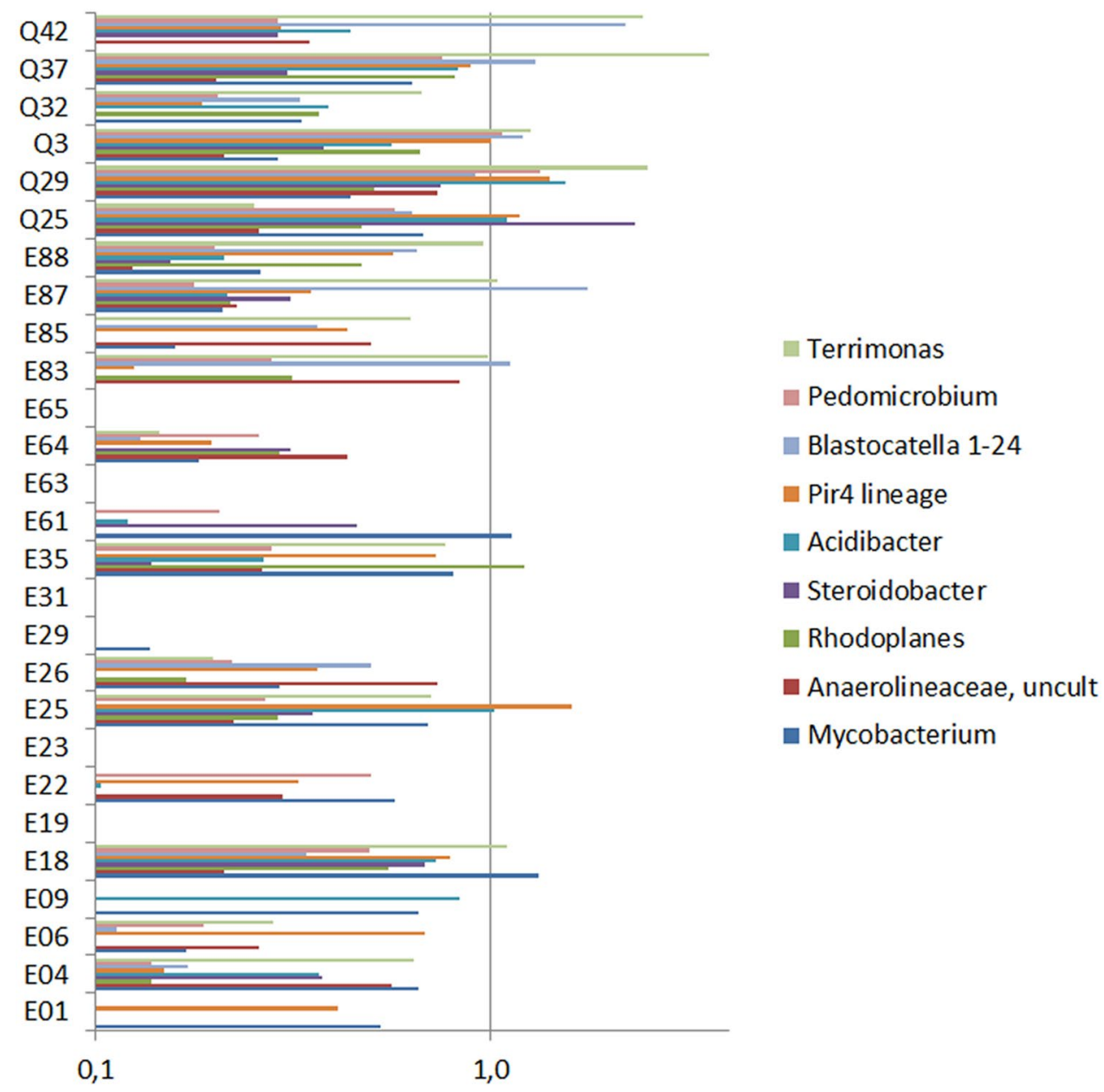

In many cases, the sequences allowed to assign bacterial groups down to the genus level. In other cases, the identification with higher taxonomical levels could be achieved, only. The lowest identified level was always referenced as "Operational Taxonomic Unit" (OTU) for the comparison of bacterial diversity and for the calculation of the Shannon index.

\section{Results and discussions}

There are some OTUs which are present in all samples and strongly prominent in most of them; among them are Blastococcus, Ferruginibacter, Haliangium, Iamia, Massilia, Bdellovibrio, Pseudonocardia and Sphingomonas. Beside these types, there is another group of OTUs which could be identified in the overwhelming part of the soil samples, but are missing in a few samples; among them are Gaiella, Pseudomonas, Rubrobacter, Anaerolineaceae (uncult.). and Planctomycetaceae/Pir4 lineage.
In addition, there exist a group of OTUs which includes highly abundant types in one group of soil samples (group I), but which are very low or would not be identified in another group of samples (group II). This significant difference concerns the nine OTUs shown in Fig. 2. This group of bacteria is dominant or at least significantly present in about six samples and very low in other samples. Other samples contain a part of these organisms in significant amounts, only. Thus, the presence and absence of these bacteria allow a clear differencing between these two groups of soil samples. A certain confirmation of the relations between the members of the both groups was also found in the principle component analysis of the quantitative distribution of the 100 most frequent OTUs (Fig. 3). Both groups are marked by a characteristic distribution in the binary correlation plots of the first, second and third principle components. But this quantitative effect is much weaker than the distinguishing by the presence or absence of the microorganisms displayed in the abundance graph (Fig. 2).

More significantly are the differences in some binary frequency correlations. The content of Frankiales, 

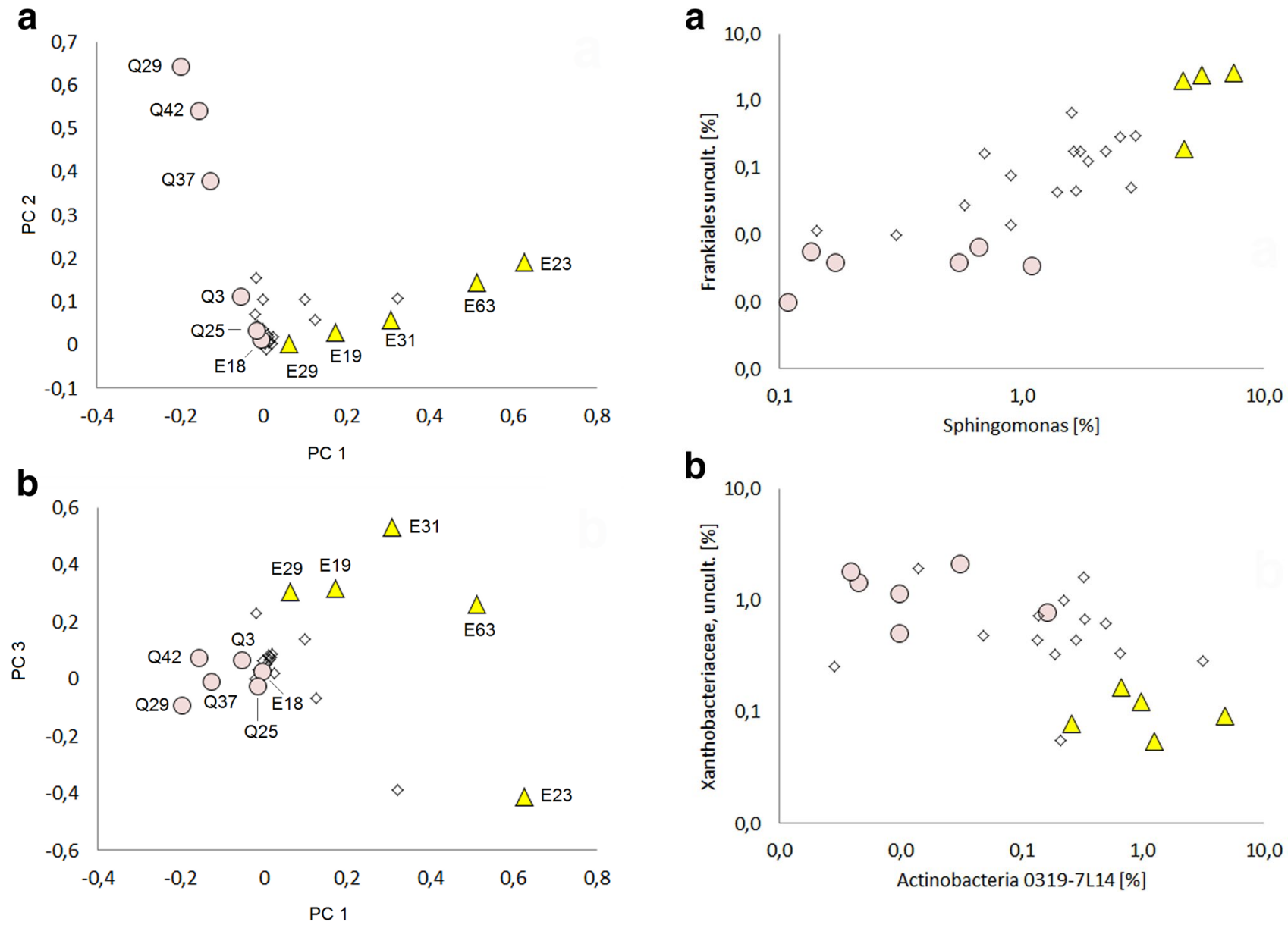

Fig. 3 Principle component analysis of the 100 most abundant OTUs in the investigated soil samples: circles (group I): samples of higher abundant OTUs shown in Fig. 2, triangles (group II): samples of low abundant OTUs shown in Fig. 2; small diamonds: other samples a PC1/PC2 correlation, b PC1/PC3 correlation

Sphingomonas, Actinobacteria 0319-7L14 and a uncultivated taxonomical group of Xanthobacteriaceae seems to indicate the group character: Group I samples, for example, tend to have lower contents of Frankiales and Spingomonas; group II samples have higher contents of these both bacteria (Fig. 4a). In contrast, a negative correlation was observed, for example, between Xanthobacteriaceae and Actinobacteria 0319-7L14 (Fig. 4b). Examples for large differences in the presence of selected OTUs in soil samples are shown in Fig. 5.

Beside the OTUs with high average abundance, there are a lot of types present at low content. Among them, there have been found rare types, which are identified in several samples of the three regions (Fig. 6) and which are related to special environmental conditions.

Three or more Hadesarchaeota sequences have been found in eight of the 27 samples, but not in samples from the region around Rodishain and Uftrungen. In total, 63

Fig. 4 Correlation of abundance (arbitrary units) of two pairs of frequent OTUs in the investigated soil samples; circles (group I): samples of higher abundant OTUs shown in Fig. 2, triangles (group II): samples of low abundant OTUs shown in Fig. 2; small diamonds: other samples

Hadesarchaeota sequences have been identified. Their spatial distribution is shown in Fig. 7d. Populations of Hadesarchaeota have been found in variable part of the world as in a South African gold mine, in the White Oak river estuary and in the Yellowstone National Park. These are all habitats of extreme conditions with a temperature of about $70^{\circ} \mathrm{C}$ and highly alkaline environment. The organisms are strongly related to other anaerobic bacteria, can oxidize $\mathrm{CO}$ to $\mathrm{CO}_{2}$, liberate molecular hydrogen and seem to represent an important taxonomical unit of cosmopolitan subsurface archaea [4]. It seems to be obvious that a surface distribution of this type of organisms from outside of the mining region is much less likely than an origin from the sediments brought to the surface by the ancient mining activities.

Seven soil samples contained between 6 and 47 reads of $16 \mathrm{~S}$ rRNA sequences of Rubritepida (Fig. 6b). This genus represents an aerobic thermophilic Alphaproteobacterium and was recently isolated from a hot spring at Egerszalok 


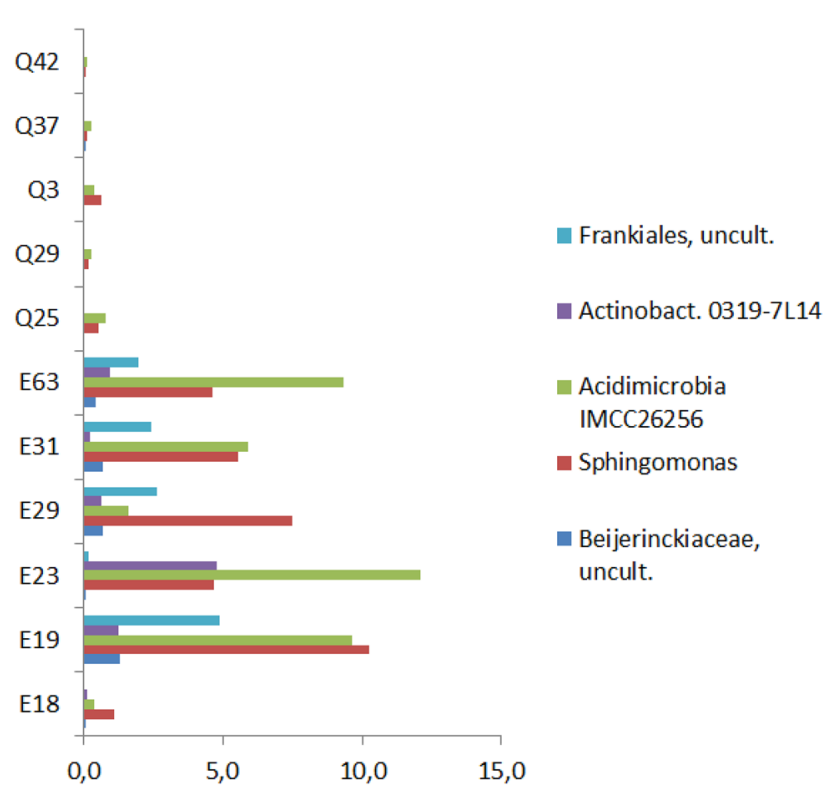

Fig. 5 Percentage of five selected OTUs with high differences in their abundance in eleven selected soil samples

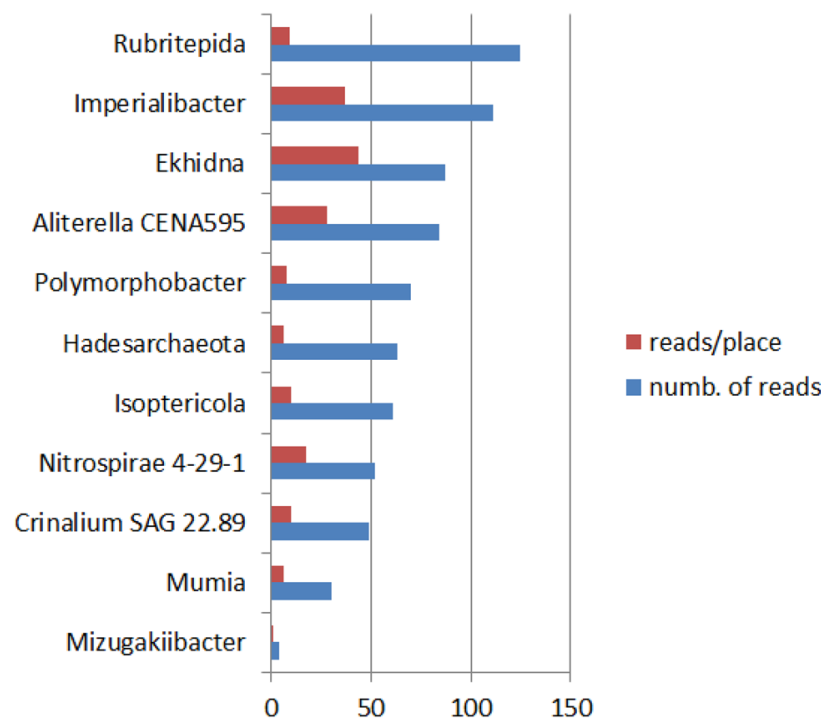

Fig. 6 Abundance (number of reads) of selected rare types in the investigated soil samples (red: average number of reads per place with the related presence; blue: total number of reads)

in Hungary [3]. Another aerobic genus, Polymorphobacter, which was originally isolated from an Antarctic rock [9] was found in several samples of all three regions (Fig. 7a).

Several rare microorganisms have been found in only a few soil samples from the ancient mining regions or are present in only one sample. Among them, there are halotolerant types as Isoptericola [33], which was present in a significant amount in sample E25 (51 reads), Alitererella [26] in sample E63 (62 reads). Imperialibacter was found in samples E1 (74 reads) and E85 (36 reads). Ekhidna [2] was significantly present in sample E85, only (86 reads). A strain of the new genus Imperialibacter (Bacteriodetes) was isolated from Permian groundwater [29]. Mumia was isolated from mangrove soil in Malaysia and belongs to the family Nocardioidaceae [19]. Mizugakiibacter is a thermophilic organism which was isolated from a freshwater sediment in Japanese [16].

It is obvious from the obtained 16S rRNA data that the found special thermophilic and halotolerant types are not presenting a whole ancient microbial community. Tectonic processes, heat exposure during the geologic development as well as the technologies and movement of material during the exploitation of mines had influenced the composition of bacterial communities on the surface around the mining places. The majority of soil bacteria reflected by the obtained $16 \mathrm{~S}$ rRNA profilings have probably not an origin from the ground. But, the above-mentioned special types suggest the possibility that ancient bacteria could be brought from the grounds to the surface by the mining activities and could be related to a kind of "trace of ancient ecological situation" in the recent soil microbial community.

\section{Conclusions}

The $16 \mathrm{~S}$ rRNA profiling of the investigated soil samples from three ancient copper mining areas of the East Harz regions reflects special compositions in the bacterial soil communities. Among others, several rare-type microorganisms have been identified, which are related to extreme environmental conditions. Despite the fact that single of these strains might be transferred occasionally from outside to the investigated places, the appearance of some of the types on several places and the total of these organisms might support speculation about an origin of these organisms from the mines. It is probable that the organisms or at least their DNA survived over the last decades or even the centuries since the historical mining activities. In addition, it has to be taken in mind the principle possibility that bacteria could survive over 250 million years since the time of copper ore deposition in Zechstein formation (late Perm; [6]). Such an assumption could include the possibility that extremophiles are not only transported through the atmosphere, but that very old microorganisms from deep geological layers of the copper mining region could be liberated to the environment and contribute to the recent local bacterial soil communities, too. It is assumed that such old organisms can also be liberated from geological sediments by natural erosion processes from time to time. Then, they could be re-activated, distributed and could contribute to the recent diversity of soil microbial communities. Future investigations should 
Fig. 7 Presence of selected rare types at the soil sampling places

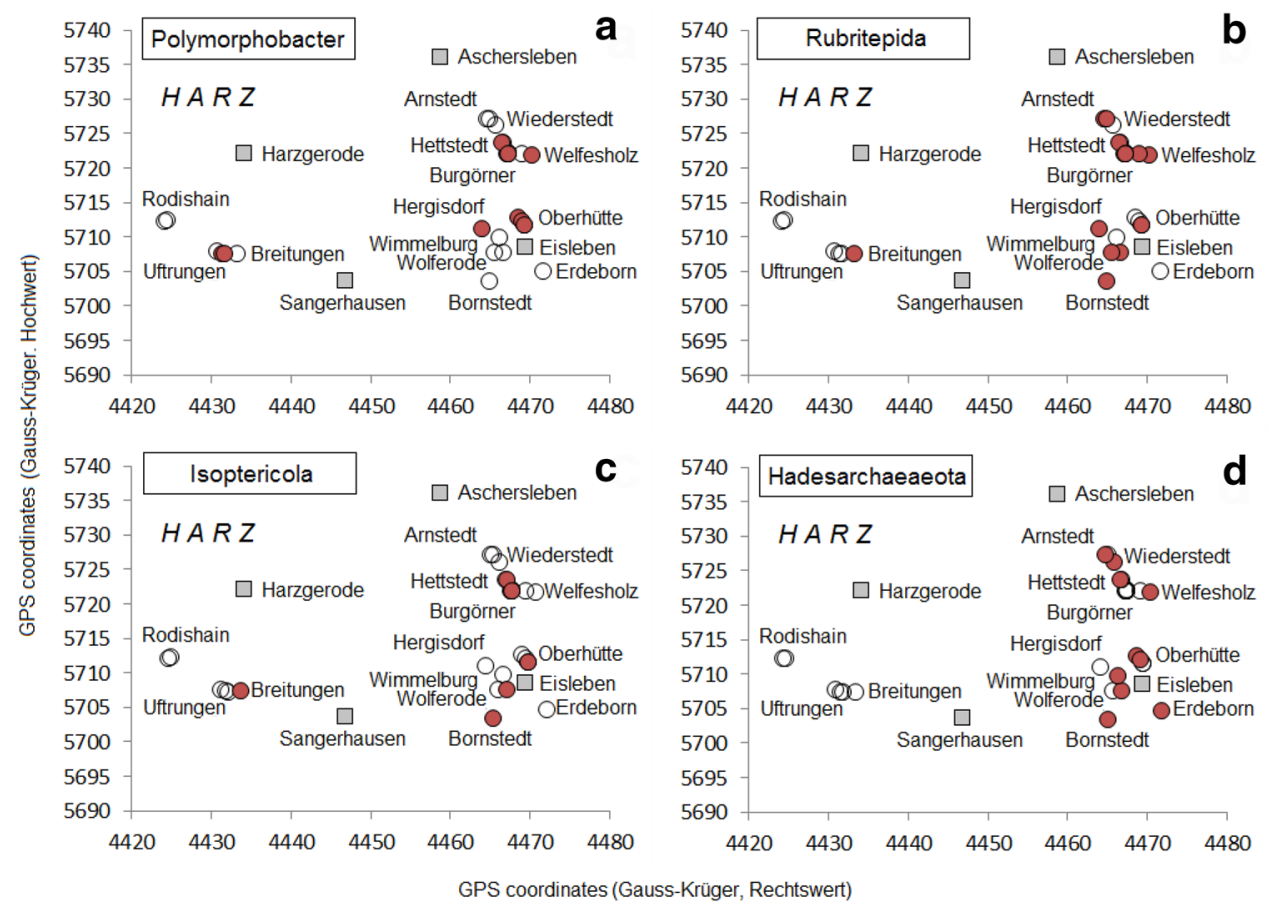

5. Camacho C, Coulouris G, Avagyan V, Ma N, Papadopoulos J, Bealer K, Madden T (2009) BLAST+: architecture and applications. BMC Bioinform 10:421

6. Clement M (1996) Tausend Jahre Metallerzbergbau in Mitteleuropa (Verlag Glückauf GmbH Essen)

7. Fierer N, Jackson RB (2006) The diversity and biogeography of soil bacterial communities. PNAS 103:626-631

8. Fierer N, Lennon JT (2011) The generation and maintenance of diversity in microbial communities. Am J Bot 98:439-448

9. Fukuda W, Chino Y, Araki S, Kondo Y, Imanaka H, Kanai T, Atomi H, Imanaka T (2014) Polymorphobacter multimanifer gen. nov., sp. Nova, a polymorphic bacterium isolated from Antarctic white rock. Int J Syst Evol Microbiol 64:2034-2040

10. Haferburg G, Kothe E (2010) Metallomics: lessons for metalliferous soil remediation. Appl Microbiol Biotechnol $87: 1271-1280$

11. Hong C, Si Y, Xing Y, Li Y (2015) Illumina MiSeq sequencing investigation on the contrasting soil bacterial community structures in different iron mining areas. Environ Sci Pollut Res 22:10788-10799

12. Itcus C, Pascu MD, Brad T, Persoiu A, Purcarea C (2016) Diversity of cultured bacteria from the perennial ice block of Scarisoara Ice Cave, Romania. Int J Speleol 45:89-100

13. Jiao S, Luo YT, Lu MM, Xiao X, Lin YB, Chen WM, Wei GW (2017) Distinct succession patterns of abundant and rare bacteria in temporal microcosms with pollutants. Environ Pollut 225:497-505

14. Jones SE, Lennon JT (2010) Dormancy contributes to the maintenance of microbial diversity. PNAS 107:5881-5886

15. Köhler JM, Kalensee F, Günther PM, Schüler T, Cao J (2018) The local ecological memory of soil: majority and minority components of bacterial communities in prehistoric urns from Schöps (Germany). Int J Environ Res 12:575-684

16. Kojima H, Tokizawa R, Fukui M (2014) Mizugakiibacter sediminis gen. nov., sp. Nov., isolated from a freshwater lake. Int J Syst Evol Microbiol 64:3983-3987 
17. Korehi $\mathrm{H}$, Blothe $M$, Schippers A (2014) Microbial diversity at the moderate acidic stage in three different sulfidic mine tailings dumps generating acid mine drainage. Res Microbiol 165:713-718

18. Korzhenkov AA, Toschakov SV, Bargiela R et al (2019) Archaea dominate the microbial community in an ecosystem with lowto-moderate temperature and extreme acidity. Microbiome 7:11

19. Lee LH, Zainal N, Azman AS, Mutalib NS, Hong K, Chang KG (2014) Mumia flava gen. nov., sp. Nov., an actinobacterium of the family Nocardioidaceae. Int J Syst Evol Microbiol 64:1461-1467

20. Liu J, Hua ZS, Chen LX et al (2014) Correlating microbial diversity patterns with geochemistry in an extreme and heterogeneous environment of mine tailings. Appl Environ Microbiol 80:3677-3686

21. Margesin R, Siles JA, Cajthaml T, Ohlinger B, Kistler E (2017) Microbiology meets archaeology: soil microbial communities reveal different human activities at archaic Monte lato (sixth century BC). Microb Ecol 73:925-938

22. Mendez-Garcia C, Mesa V, Sprenger RR et al (2014) Microbial stratification in low pH oxic and suboxic macroscopic growths along an acid mine drainage. ISME J 8:1259-1274

23. Miskin I, Rhodes G, Lawlor K, Saunders JR, Pickup RW (1998) Bacteria in post-glacial freshwater sediments. Microbiology SGM 144:2427-2439

24. Pruesse E, Peplies J, Glöckner FO (2012) SINA: accurate high throughput multiple sequence alignment of ribosomal rna genes. Bioinformatics 28:1823

25. Quast C, Pruesse E, Yilmaz P, Gerken J, Schweer T, Yarza P, Peplies J, Glockner FO (2013) The SILVA ribosomal RNA gene database project: improved data processing and web-based tools. Nucleic Acids Res 41:D590-D596

26. Rigonato J, Gama WA, Alvarenga DO et al (2016) Aliterella atlantica gen. nov, sp nov., and Aliterella Antarctica sp nov., novel members of coccoid Cynaobacteria. Int J Syst Evol Microbiol 66:2853-2861

27. Schmidt G, Frühauf M (2000) Die Bedeutung der Halden des Mansfelder Kupferschieferbergbaus als potentielle Schwermetallemittenten. Schriftenreihe des Mansfeld Museums (Neue Folge) 5:78-83

28. Stan-Lotter $\mathrm{H}$, Pfaffenhuemer $M$, Legat A, Busse HJ, Radax $C$, Gruber C (2002) Halococcus dombrowskii sp. nov., an archaeal isolate from a Permian alpine salt deposit. Int J Syst Evol Microbiol 52:1807-1814

29. Wang H, Li H, Zheng T, Hill RT, Hu X (2013) Imperialibacter roseus gen. nov., sp nov., a novel bacterium of the family Flammeovirgaceae isolated from Permian groundwater. Int J Syst Evol Microbiol 63:4136-4140

30. Weizhong L, Godzik A (2006) Cd-hit: a fast program for clustering and comparing large sets of protein or nucleotide sequences. Bioinformatics 22:1658-1659

31. Xiang SR, Yao TD, An LZ et al (2005) Vertical quantitative and dominant population distribution of the bacteria isolated from the Muzagata ice core. Sci China Ser D Earth Sci 48:1728-1739

32. Yilmaz P, Parfrey LW, Yarza P, Gerken J, Pruesse E, Quast C, Schweer T, Peplies J, Ludwig W, Glockner FO (2014) The SILVA and "all-species living tree project (LTP)" taxonomic frameworks. Nucleic Acids Res 42:D643-D648

33. Zhang YQ, Schumann P, Li WJ, Chen GZ, Tian XP, Stackebrandt E, Xu LH, Jiang CL (2005) Isoptera halotolerans sp. nov., a novel actinobacterium isolated from saline soil from Qinghai Province, north-west China. Int J Syst Evol Microbiol 55:1867-1870

Publisher's Note Springer Nature remains neutral with regard to jurisdictional claims in published maps and institutional affiliations. 